\title{
15
}

\section{The Boundaries of Budgets: Why should individuals make spending choices about their health and social care?}

Catherine Needham ${ }^{1}$

\section{Introduction}

The postwar welfare states of many countries set up a division between cash transfers and state services, based on the assumption that citizens were the best purchasers of some services (for example, food and clothing) and that the state could purchase others more effectively on their behalf (for example, health and social care). However, a number of interrelated developments have increased the scope of services that are allocated in a cash form or via a notional budget - for example, personal budgets for care in England and the National Disability Insurance Scheme (NDIS) in Australia. As the NDIS is at an early stage of implementation, this chapter draws on the longer established English experience of personal budgets to consider the underlying

1 This chapter was first published as an article for the London-based think tank The Centre for Health and the Public Interest. It is reproduced here with kind permission from the centre. 
rationale for transferring financial control down to the level of the individual. In particular, the chapter interrogates four claims that are made about individualised budgets:

1. They improve outcomes for individuals.

2. They extend choice and control to citizens, which they should have as a matter of right.

3. They make citizens more financially literate, contributing to service efficiency.

4. They correct system-level failings in public services.

\section{Personal budgets in England}

In England, initiatives to transfer resources to disabled people as direct payments began in the 1980s and were given legal endorsement in the 1996 Community Care (Direct Payments) Act. Local governments, which have responsibility for social care, are now expected to move all eligible users on to a personal budget, which may be in the form of a direct payment to the individual, a managed budget (with funds remaining with the local authority) or a combination of the two. This is part of the broader personalisation agenda within social care to increase choice and control, improve prevention, enhance social capital and improve access to universal services (HMG 2007; Needham 2011). Personal budgets are now held by more than 50 per cent of older and disabled people, although take-up of direct payments has been much lower: 7 per cent of older people are in receipt of a direct payment, as are 25 per cent of people with learning disabilities (Age UK 2013).

The individualised funding agenda is not confined to social care. Personal health budgets have been trialled in the National Health Service (NHS) for people with a range of conditions such as diabetes and asthma and for users of mental health services (DH 2009; Forder et al. 2012). These budgets are now being rolled out nationally and localities are being encouraged to offer them to people with long-term conditions. Patients can choose to manage the money themselves, following new legislation on direct payments in health. Alternatively, they can work with health professionals or a third party to identify how to allocate a notional or managed budget. Budgets are also being introduced for the parents of children with disabilities and special 
educational needs, and are being proposed for a range of sectors such as adoption services and rough sleepers. Individualised budgets are also part of the Department of Work and Pensions' Right to Control initiative to make it easier for disabled people to access work (DWP 2008). The consolidation of a range of benefits, including housing benefits, into a monthly 'universal credit' paid directly to tenants (rather than the housing element going directly to the landlord) could arguably be seen as part of the same trend (Brown 2012). This builds on the earlier model of the Local Housing Allowance (LHA) through which eligible tenants in private rented accommodation receive their housing benefit directly. If tenants were able to secure a cheaper rent they could keep the additional money or they could top up the rent to access more expensive accommodation (DWP 2006).

The increasing disaggregation of budgets down to the individual level in the form of cash or a notional allocation has generated intense debate in the various sectors in which it has occurred. The most extensive debates to date have been within social care, where the policy is furthest advanced and where a set of recurring themes dominates the academic and practitioner literatures: do personal budgets turn care recipients into consumers or do they offer the means for people to become active citizens? Do personalised care services empower the budget holder or do they offload responsibilities from the state to the individual? Can the rights of older and disabled budget holders be respected at the same time as the rights of carers and care workers? Such debates are inherently recursive because the terminology (citizen, consumer, and so on) is unstable, experiences are heterogeneous and hard to measure and policy and funding contexts are constantly shifting.

To contribute to these debates without repeating them, this chapter interrogates the various rationales that have been put forward to justify the devolution of budgets down to the individual. While neoliberal retrenchment of the state is a catch-all explanation often proffered within the literature, the discussion here will focus on a range of claims that go beyond that rather simplistic account. Four claims are examined here: individualised budgets improve outcomes for individuals; budgets extend choice and control to citizens, which they should have as a matter of right; budget holding has an important educative function for individuals, enabling them to share in a common citizenship; and budgets correct system-level failings in public services. The discussion below argues that individual budgets 
have proven value in meeting claims one and two, but not in meeting claims three and four. The discussion focuses primarily on personal budgets in social care since this is the sector in which the evidence base is most mature, but also considers the existing or likely impacts in other sectors where possible.

\section{Personal budgets lead to better individual outcomes}

There is a growing body of evaluative data from social care indicating that people derive benefits from holding a personal budget to make care choices. The Individual Budgets Evaluation Network (IBSEN) funded by the UK Department of Health found that '[p]eople receiving an IB [individual budget] were significantly more likely to report feeling in control of their daily lives, welcoming the support obtained and how it was delivered, compared to those receiving conventional social care services' (IBSEN 2008: 2). These findings were strongest for people using mental health services and weakest for older people (Glendinning et al. 2008). The National Personal Budget survey conducted by Think Local, Act Personal, Lancaster University and the social innovation network In Control found that 'substantial majorities of people reported personal budgets having a positive impact' (Hatton and Waters 2011: 22). People receiving their social care budget as a direct payment have more transformative outcomes than people whose budgets are managed on their behalf by the local authority or a third party. According to the National Personal Budget survey: 'Whilst all personal budget holders reported positive outcomes, those managing the budget themselves as a direct payment reported significantly more positive outcomes than people receiving council managed budgets' (Hatton and Waters 2011: 4).

Within the health sector, a large government-funded evaluation of personal health budgets found that such budgets produced 'valued well-being benefits' (Forder et al. 2012: 156). These benefits came not from improved health outcomes (where the evaluation did not find statistically significant improvements) but from improvements in care-related quality of life and psychological well-being, which the 
researchers refer to as 'higher-order' aspects (Forder et al. 2012: 78). The psychological benefits of giving people more control are well known. As Glasby and Littlechild put it:

There is a large literature in the field of psychology to suggest that control is essential to wellbeing and an important element in shaping people's lives and their susceptibility to stress ... For many direct payments recipients, enhanced choice and control increased their selfconfidence, morale and emotional and psychological health in a range of areas. (Glasby and Littlechild 2009: 117-18)

The mechanism through which personal budgets improve well-being and other outcomes is often assumed to be the purchasing power that comes with financial control (Tyson 2007). A member of In Control, a social enterprise set up to promote personal budgets, told the author in an interview: 'Until I've got hold of the money, or at least I'm directing the way that that money's spent, that provider is never going to listen to me. It is the power of the pound, the power of having the money is the bit that makes the difference' (Needham 2011: 55). A feature of the evaluations of budget holding across social care, the NHS and rough sleepers is, however, the value people place on the support planning process in which they sit down with a professional or other support worker and talk about their needs, preferences and capabilities. As a participant in the rough-sleepers' pilot put it:

I've got to be honest here, it wasn't just the individual budget, it was the fact there was [a coordinator] there as well ... We was meeting [regularly] to discuss it, and I'd actually gone from the stage of wanting nothing to do with these people, to actually looking forward to seeing them. (Hough and Rice 2010: 8)

Similar findings - about the value of building relationships with care providers - have emerged from the social care and health budget evaluations, highlighting that the one-to-one support that accompanies a budget is at least as important to improving well-being as the money itself (Needham 2014).

\section{A matter of right}

A second rationale for personal budgets is a rights-based argumentnamely, that such budgets are designed to allow people to make the sorts of choices about their health and social care that are theirs by 
right to make. Within social care, people are choosing the times they get up and go to bed, the timing and content of meals, how they receive personal care, as well as how they spend their days - issues on which they can reasonably expect to have autonomy. The personalisation reforms are premised on an assumption that people are 'experts on their own lives' (Poll 2007), and social workers are expected to work within that paradigm. Within the health sector, the boundaries between clinical knowledge and patient knowledge have not shifted so far, but the rise of expert patient programs highlights a growing confidence that there is a range of health conditions on which patients have a normative claim to expertise and autonomy.

This is of course not to claim that making spending choices about health and social care is not a complex and uncertain process in which people need support. The National Personal Budget survey found that the 'single most commonly commented upon issue in the survey was a lack of clarity, often regarding how money could or couldn't be used, but also concerning other aspects of personal budgets as well' (Hatton and Waters 2011: 19). Inequalities in the capacity of citizens to navigate complex care systems have been a concern raised by many people, particularly in the context of personal budgets (Riddell et al. 2005; Barnes 2008; Glendinning 2008; Slasberg and Hatton 2011). Advocates of personalisation argue that the care systems that predated personal budgets were themselves characterised by complexity, lack of transparency and inequity. Hatton points out that these issues have not been created by personal budgets and should not be a reason to reject them: 'Plenty of evidence exists that social care services tend to be directed towards those with the skills, tenacity and resources to negotiate byzantine systems. However, this is not a specific issue concerning direct payments - it is a pervasive one found throughout social care' (Slasberg and Hatton 2011). The aim of personalisation advocates was to simplify the complex process of social care assessment and allocation of services into a transparent series of steps; an ongoing frustration for reformers has been the tendency of government to overly bureaucratise the allocation and monitoring of budgets (Routledge 2011). 


\section{Financial inclusion}

A feature of welfare reform in the United Kingdom over several decades has been the encouragement of individual financial literacy and responsibility with the avowed aim of incorporating people into a common citizenship (Finlayson 2009). The New Labour Government's Child Trust Fund was an exemplar of this approach. Efforts to give citizens more direct control over financial resources through personal budgets could be seen as an extension of this educative function. The government sets out the rationale for the LHA, for example, as follows:

By paying LHA direct to the customer it ensures they take on the personal responsibility of paying the rent to the landlord and helps develop the budgeting skills unemployed people will need when they move into the workplace. It also plays a part in the wider cross Government strategy of greater 'financial inclusion'. (DWP n.d.)

Personal budgets and health budgets can, similarly, be linked to the enhancement of financial literacy and the promotion of financial inclusion. The payments give people choices that may previously have been denied to them and incentivise careful budgeting since people can benefit directly from more frugal use of resources. Writing in a social care setting, Spandler (2004: 193) notes that '[p]owerful personal incentives exist for recipients to use their money wisely, efficiently and prudently because their survival and independence depend upon it'. As well as being more frugal, the service user may take on some of the hidden costs of the system, 'because the user often acts as an employer and budget holder, he/she soaks up much of the administrative and management costs. This may mean that recipients can get greater levels of social care at no greater cost' (Spandler 2004: 193).

Welfare reforms that purport to build civic inclusion and financial literacy through individualised financial labour and increased exposure to risk have, however, drawn widespread criticism (Ferguson 2007; Barnes 2008; Beresford 2008; Finlayson 2009). Writing in a care context, Scourfield (2007: 113) notes that '[d]irect payments fit comfortably with the project to transform the culture of the public, private and informal care sectors around principles of innovation, risk taking and enterprise'. This can perhaps be understood as a distortion of the citizen's income arguments put forward by the left, with financial 
inclusion being promoted not as part of an equal citizenship but on condition of compliance with activation policies around work and the family (Yeatman et al. 2009).

\section{Fixing the system}

There is great optimism among personalisation advocates about the potential for personal budgets to fix the problems that are evident in the existing system of social care support. The ambition of social enterprises like In Control, which developed much of the early thinking and design of personal budgets, has been very much system-wide, recognising the limitations of the social care market. Personal budgets are seen as a way in which individuals can tackle some of the many limitations of existing social care provision, whether it is risk-averse professionals limiting people's choices, large block contracts proving too restrictive to meet people's support needs or private companies providing a very poor standard of care (Land and Himmelweit 2010). The vulnerabilities of a care market funded by venture capital were starkly demonstrated with the collapse in 2011 of the Southern Cross Group, a large private provider of residential care homes in the United Kingdom. Many homes closed and others had to be picked up by state or other providers at very short notice, creating uncertainty and distress for many older people and their families (BBC 2011).

These structural problems have a knock-on effect on the social care workforce, which, it is well known, is low paid, with poor training standards and insecure working conditions (Ungerson 1997; Low Pay Commission 2009). A report into social care by the Equality and Human Rights Commission (EHRC 2011: 7) found 'serious, systemic threats to the basic human rights of older people who are getting home care services'. This conclusion echoed the findings of the Time to Care report into the home care sector, published by the Commission for Social Care Inspection (CSCI 2006: 2), which found 'the sector itself is a fragile one, that is struggling already to provide services of sufficiently high quality for those who need them now ... A gap appears to be developing between what people themselves want and need, and what is on offer from statutory services'. 
Despite the widespread recognition of these systemic failings, there is only limited scope to fix them through the market power of individual budget holders. Workforce changes may be brought about as more people shift to employing a personal assistant, rather than using social care agencies. Personal assistants have been found to have higher job satisfaction than agency workers (IFF Research 2008); however, they again can be a poorly paid and isolated workforce with little access to training (Ungerson 1999). Innovative third-sector organisations providing quality care services are expected to benefit from the market stimulus of lots of individual commissioners but may simply be unable to operate on the basis of such an insecure funding stream (Dayson 2011).

To understand the limitations of individualised budgets as a way to challenge system-level inadequacies, it is useful to study the experience of self-funders in the care system. Unlike 'early adopters' of personal budgets and direct payments, who may have characteristics that make them particularly well suited to managing care spending (and therefore from whom it may be difficult to generalise about mainstream impacts), self-funders include all those who are ineligible for means-tested local authority funding, which may say little about their support networks or financial acumen. They are large in number -40 per cent of older people are estimated to make some financial contribution to their care costs (Forder 2007) - and many have purchased care over a long period, making them a useful comparator group. Self-funders have not been well studied and have rarely been evoked in personalisation debates to inform understandings of how financial control intersects with care, perhaps because the drive for direct payments has come from younger disabled people for whom self-funding is less prevalent (Lloyd 2010).

A report on self-funders commissioned by the Putting People First Consortium noted:

For some people there was a profound sense of 'powerlessness' and lack of control over their own financial resources, coupled with some real fear over what would become of them if their savings ran dry ... It is clear that having sufficient resources to be a self-funder does not automatically give people greater control over their situation, and meaningful choices are often lacking. (Melanie Henwood Associates 2010: 48, 50) 
It is certainly the case that the existence of a large bloc of self-funders has not led to the emergence of affordable, good-quality care for older people, as the endemic problems in the quality of home care services attests (EHRC 2011). A poorly regulated market intersects with the intimate nature of social care (and its complex interaction with vulnerability and dependence) to make individual market efficacy relatively weak (Rummery and Fine 2012).

The need for a system-wide fix is very apparent in social care, but much less so in health, where international measures indicate that the NHS continues to perform well in terms of quality (Commonwealth Fund 2014). The problems that personal health budgets seem designed to address are the growing financial pressures of the rising numbers of people with chronic health conditions and the value (normative and financial) of recruiting them as self-managers of those conditions. The funding landscape in health is also so different to that in social care that it is hard to read across, given that the NHS is a universal service whereas social care is means tested. There are currently no NHS analogues to social care self-funders, although with the likelihood of an increasingly commercial basis for many NHS services, there is an increased possibility of top-up payments being introduced to supplement a core set of NHS services, exposing health budget holders to the same market vulnerabilities that are very familiar from social care. The personal health budget evaluation noted: 'Policy makers should anticipate that the use of personal health budgets is likely to result in a higher level of expenditure going to "non-conventional" [that is, non-NHS] providers. Further research is required to better understand the scale of these changes' (Forder et al. 2012: 155).

\section{Conclusion: Arguing for budgets}

Personal budgets have been a hugely positive intervention for some people using social care services, particularly those who have been able to self-manage the money as a direct payment. There have also been benefits for people holding personal health budgets. The tentative nature of these findings, however, should be noted: they have tended to be observed among groups of 'early adopters', the benefits have been more around well-being than around health outcomes and they may be more attributable to the time spent on support planning than 
the time spent on the spending choices made. Nonetheless, there are sufficient data to see that there are some positive individual outcomes for people who choose to make care and health spending choices themselves.

There is also a rights-based rationale for including people more directly in choices about health and social care. Making choices via a budget is a complex process and the ability to do so is not shared equally, but there are intrinsic and instrumental reasons for believing that individuals - with families and communities - ought to play a key role in making those choices when they want to do so. The difficulties people face in making effective decisions about care should be a reminder of the importance of ensuring that people are well supported, particularly through peer support and advocacy networks that can draw on shared experience. It is also important to reaffirm that people's care choices and eligibility criteria do not have to be located in ever more complex bureaucracies, which even experienced observers find difficult to fathom.

The claim that controlling money is a valuable educative process is harder to sustain, having its roots in a view of 'active welfare' that is premised on forcing people to take on responsibilities. Not everyone will welcome the risks and complexities of being a budget holder, and making this compulsory is anathema to the principles that animated the independent living campaigns for direct payments.

The argument that budgets themselves will fix systemic problems in care provision is also unconvincing. There are distinctive attributes of care that act as important intervening variables in understanding how market changes play out. The self-funder experience highlights the complex interplay of market and social norms in a sector in which system-level marketisation is well established. A highly commodified sector has delivered a poor quality of care to those with and without their own purchasing power, largely because neither local authorities nor individuals have sufficient resources to meet the real costs of quality care or to demand effective accountability from providers.

Rather than seeing budgets as a way of giving people leverage to fix the problems of the social care market, they can be viewed as an effective tool to deliver change for some service users, although probably at the fringes rather than in the mainstream. Mainstream benefits may 
be best harnessed through focusing on the relational aspects of support planning, drawing on a series of evaluation findings about the value people derive from talking at length to a professional or peer planner about their capabilities and aspirations. The implementation of individualised budgets in England at a time when austerity so dominates the welfare terrain makes it hard to imagine that these relational benefits can be sustained. As the NDIS gathers momentum in Australia amid promises of a massive and sustained increase in funding, it is vital that good-quality information and advocacy are in place so that people with budgets can build relationships and communities and not just pick care items off a shopping list.

\section{References}

Age UK. 2013. Making Managed Personal Budgets Work for Older People. London: Age UK. Available from: ageuk.org.uk/professionalresources-home/services-and-practice/care-and-support/ personalisation-hub/making-personal-budgets-work-for-olderpeople/ (accessed 29 July 2015).

Barnes, M. 2008. 'Is the personal no longer political?' Soundings 39: 152-59.

Barnes, M. 2011. 'Abandoning care? A critical perspective on personalisation from an ethic of care.' Ethics and Social Welfare 5(2): 153-67.

Beresford, P. 2008. 'Whose personalisation?' Soundings 40: 8-17.

British Broadcasting Corporation (BBC). 2011. 'Southern Cross set to shut down and stop running homes.' $B B C$ News, 11 July. Available from: bbc.com/news/business-14102750 (accessed 29 July 2015).

Brown, C. 2012. 'Tenants on direct payment pilots pay rent on time.' Inside Housing, 17 August.

Commission for Social Care Inspection (CSCI). 2006. Time to Care. London: CSCI. 
Commonwealth Fund. 2014. Mirror, Mirror on the Wall, 2014 Update: How the US health care system compares internationally. Washington, DC: Commonwealth Fund. Available from: commonwealthfund.org/ publications/fund-reports/2014/jun/mirror-mirror (accessed 29 July 2015).

Dayson, C. 2011. 'The personalisation agenda: Implications for organisational development and capacity building in the voluntary sector.' Voluntary Sector Review 2(1): 97-105.

Department for Work and Pensions (DWP). n.d. Local Housing Allowance: Frequently asked questions. London: DWP. Available from: dwp.gov. uk/local-authority-staff/housing-benefit/claims-processing/localhousing-allowance/faqs/ (accessed 29 July 2015).

Department for Work and Pensions (DWP). 2006. A New Deal for Welfare: Empowering people to work. London: Her Majesty's Stationery Office.

Department for Work and Pensions (DWP). 2008. Raising Expectations and Increasing Support: Reforming welfare for the future. London: Her Majesty's Stationery Office.

Department of Health (DH). 2009. Personal Health Budgets: First steps. London: Department of Health.

Department of Health (DH). 2010. A Vision for Adult Social Care. London: Department of Health.

Equality and Human Rights Commission (EHRC). 2011. Close to Home: An inquiry into older people and human rights in home care. London: Equality and Human Rights Commission.

Ferguson, I. 2007. 'Increasing user choice or privatizing risk: The antinomies of personalization.' British Journal of Social Work 37(3): 387-403.

Finlayson, A. 2009. 'Financialisation, financial literacy and asset-based welfare.' British Journal of Politics and International Relations 11(3): 400-21. 
Forder, J. 2007. Self-funded social care for older people: An analysis of eligibility, variations and future projections. PSSRU Discussion Paper 2505. Personal Social Service Research Unit and CSCI, University of Kent, Canterbury.

Forder, J., K. Jones, C. Glendinning, J. Caiels, E. Welch, K. Baxter, J. Davidson, K. Windle, A. Irvine, D. King and P. Dolan. 2012. Evaluation of the Personal Health Budget Pilot Programme. London: Department of Health.

Glasby, J. and R. Littlechild. 2009. Direct Payments and Personal Budgets: Putting personalisation into practice. Bristol: Policy Press.

Glendinning, C. 2008. 'Increasing choice and control for older and disabled people: A critical review of new developments in England.' Social Policy and Administration 42(5): 451-69.

Glendinning, C., D. Challis, J. Fernandez, S. Jacobs, K. Jones, M. Knapp, J. Manthorpe, N. Moran, A. Netten, M. Stevens and M. Wilberforce. 2008. Evaluation of the Individual Budgets Pilot Programme. York, UK: Social Policy Research Unit.

Hatton, C. and J. Waters. 2011. National Personal Budgets Survey 2011. London: Think Local, Act Personal, In Control and University of Lancaster.

Her Majesty's Government (HMG). 2007. Putting People First: A shared vision and commitment to the transformation of adult social care. London: HMG.

Hough, J. and B. Rice. 2010. Providing Personalised Support to Rough Sleepers. London: Joseph Rowntree Foundation. Available from: jrf.org.uk/publications/support-rough-sleepers-london (accessed 29 July 2015).

IFF Research. 2008. Employment Aspects and Workforce Implications of Direct Payment. Leeds: Skills for Care.

Individual Budgets Evaluation Network (IBSEN). 2008. The national evaluation of the individual budgets pilot programme. Summary Report. Social Policy Research Unit, York, UK. Available from: york.ac.uk/inst/spru/pubs/pdf/IBSENSummaryReport.pdf (accessed 17 April 2016). 
Land, H. and S. Himmelweit. 2010. Who Cares: Who pays? London: Unison.

Lloyd, L. 2010. 'The individual in social care: The ethics of care and the "personalisation agenda" in services for older people in England.' Ethics and Social Welfare 4(2): 188-200.

Low Pay Commission. 2009. National Minimum Wage Report 2009. London: Low Pay Commission.

Melanie Henwood Associates. 2010. Journeys Without Maps: The decisions and destinations of people who self-fund-A qualitative study from Melanie Henwood Associates. London: Putting People First.

Needham, C. 2011. Personalising Public Services: Understanding the personalisation narrative. Bristol: The Policy Press.

Needham, C. 2014. 'The spaces of personalisation: Place and distance in caring labour.' Social Policy and Society 14(3): 1-13.

Poll, C. 2007. 'Co-production in supported housing: KeyRing living support networks and neighbourhood networks.' In Research Highlights in Social Work: Co-production and personalisation in social care. Changing Relationships in the Provision of Social Care. Volume 49, 49-66.

Putting People First. 2011. People Who Pay for Care: Quantitative and qualitative analysis of self-funders in the social care market. London: Putting People First.

Riddell, S., C. Pearson, D. Jolly, C. Barnes, M. Priestly and G. Mercer. 2005. 'The development of direct payments in the UK: Implications for social justice.' Social Policy and Society 4(1): 75-87.

Routledge, M. 2011. 'Let's not allow bureaucracy to derail personalisation.' Community Care, 25 May.

Rummery, K. and M. Fine. 2012. 'Care: A critical review of theory, policy and practice.' Social Policy \& Administration 46(3): 321-43.

Scourfield, P. 2007. 'Social care and the modern citizen: Client, consumer, service user, manager and entrepreneur.' British Journal of Social Work 37(1): 107-22. 
Series, L. and L. Clements. 2013. 'Putting the cart before the horse: Resource allocation systems and community care.' Journal of Social Welfare and Family Law 35(2): 207-26.

Slasberg, C. and C. Hatton. 2011. 'Are personal budgets improving outcomes?' Community Care, 6 October.

Spandler, H. 2004. 'Friend or foe? Towards a critical assessment of direct payments.' Critical Social Policy 24(2): 187-209.

Tyson, A. 2007. Commissioners and Providers Together: The citizen at the centre. London: In Control and Care Services Improvement Partnership.

Ungerson, C. 1997. 'Give them the money: Is cash a route to empowerment?' Social Policy and Administration 31(1): 45-53.

Ungerson, C. 1999. 'Personal assistants and disabled people: An examination of a hybrid form of work and care.' Work, Employment and Society 13(4): 583-600.

Yeatman, A., with G. Dowsett, M. Fine and D. Guransky. 2009. Individualization and the Delivery of Welfare Services: Contestation and complexity. Basingstoke, UK: Palgrave Macmillan. 
This text is taken from The Three Sector Solution: Delivering public policy in collaboration with not-for-profits and business, edited by John Butcher and David Gilchrist, published 2016 by ANU Press, The Australian National University, Canberra, Australia. 